\title{
Los nuevos jefes democráticos. Carlos Menem y Néstor Kirchner en clave comparada
}

\section{The new democratic leaders. Carlos Menem and Néstor Kirchner in a comparative perspective}

\section{Darío Rodríguez}

Darío Rodríguez es Doctor en Ciencias Políticas, asociado al Centro de Estudios e Investigaciones Internacionales de Sciences Po / Centre National de la Recherche Scientifique, Francia.

E-mail: endelmandho@gmail.com

\section{resumen}

A partir del rol cada vez más relevante que cumplen los líderes en las democracias contemporáneas, nos proponemos en este trabajo analizar el proceso de constitución de los liderazgos de Carlos Menem y Néstor Kirchner en clave comparada. Un interrogante central organiza nuestro trabajo: ¿cómo lograron estas figuras políticas legitimar sus posiciones de autoridad? Este proceso lo analizaremos a través de la selección de dos dimensiones. La primera comprenderá el estudio del contexto histórico institucional en el que los mismos inscribieron su acción política. La segunda supondrá el análisis de la producción y movilización de una determinada idea de comunidad política. A partir de este conjunto de elementos, identificaremos las continuidades y las rupturas que definieron el proceso de constitución de los liderazgos seleccionados desde su llegada a la presidencia hasta la realización de los primeros comicios de renovación legislativa.

\section{palabras clave}

liderazgos / representación / Argentina / peronismo / Menem / Kirchner

\section{summary}

In view of the increasingly important role of leaders in contemporary democracies, we propose a comparative analysis of the constitutive processes of the presidential leaderships of Carlos Menem and Nestor Kirchner. This work thus seeks to question and characterize the processes by which both political figures legitimized their authority positions. Our assessment is two-fold: a first dimension examines the historical and institutional contexts in which their political actions were embedded. A second dimension alludes to the production and mobilisation of a political imaginary. Based on these elements, we will identify both the continuities and turning points that defined the constitutive processes for both leaderships, starting with their nominations as Presidents and extending until the holding of the first midterm legislative elections for each administration.

\section{keywords}

leadership / representation / Argentina / peronismo / Menem / Kirchner 
A principios del siglo pasado el pensador alemán, Max Weber, advertía en sus escritos sobre los riesgos que sufría un mundo cada vez más desencantado, capturado por el dominio de la lógica racional-legal y destacaba la misión capital que los liderazgos debían encarnar, en este alarmante contexto, para poder asegurar la vitalidad de las sociedades democráticas (Weber, 1991: 126). Un siglo después, si bien el escenario es otro, la actualidad de dicha afirmación se mantiene intacta. Las situaciones de crisis y las transformaciones en la vida política, que marcaron particularmente a las democracias latinoamericanas en las últimas décadas, han repotenciado el lugar que los liderazgos ocupan, en el seno de las comunidades políticas contemporáneas, a la hora de proveer los principios que dan sentido al "vivir-juntos".

En este marco, considerando que el menemismo y el kirchnerismo fueron la encarnación más viva del ciclo político que marcó a la reciente historia argentina, nos proponemos abordar el proceso de constitución de los liderazgos ${ }^{1}$ presidenciales de Carlos Menem (1989-1991) y de Néstor Kirchner (2003-2005) en clave comparada. ${ }^{2}$ Para ello, antes de identificar nuestras dimensiones de análisis, un breve paréntesis teórico se nos impone con el fin de presentar, rápidamente, cómo pensamos la idea del liderazgo político. ${ }^{3}$

Para empezar, retomamos el planteo weberiano según el cual dos atributos centrales definen a los líderes contemporáneos: la decisión política y la responsabilidad (Weber, 1991:154-167). Estos dos elementos nos permiten deducir una noción del liderazgo concebida, no en función exclusivamente de las capacidades personales que puede ostentar un individuo concreto, sino como una relación social establecida entre los representantes y los representados. ${ }^{4}$ Varias décadas después, los planteos weberianos fueron retomados por diferentes estudios con sede en la academia norteamericana. Desde esta perspectiva, se configuró un análisis sistemático sobre el fenómeno del liderazgo, ausente en Weber, a partir de dos miradas que se volvieron hegemónicas en el campo de la ciencia política: el rational choice y el neo-institucionalismo. ${ }^{5}$

En términos generales, a este conjunto de análisis le corresponde el mérito, por un parte, de pensar al liderazgo como una relación establecida entre el líder y sus seguidores ${ }^{6}$, y por la otra parte, de desarrollar una mirada de tipo interaccionista que escapa a los análisis polares anclados en la dicotomía sujeto/ estructura. Sin embargo, desde nuestro punto de vista, estos planteos adolecen de una concepción en la que la política es pensada en puros términos agregativos, limitando la acción del liderazgo a la identificación de los cálculos estratégicos del líder o a la influencia de su posición institucional. En efecto, ambas posiciones revelan diferentes reducciones que resultan, a nuestro entender, poco productivas a la hora de pensar el proceso de legitimación de los liderazgos políticos. Si avanzamos más allá de estos planteos, como también de la formulación weberiana, la idea de liderazgo se entenderá aquí en función de su articulación con la idea de la representación (Novaro, 2000: 21). Esto supone, desde nuestra mirada, pensarlo como un lazo político regido por el movimiento circular que esta idea impone (Laclau,1998: 101) pero además -y centralmente- como una 
acción de tipo instituyente: es decir como una acción que establece los sentidos que forman, siempre históricamente, toda sociedad democrática, toda comunidad política. ${ }^{7}$

Particularmente, en el escenario de la democracia de lo público (Manin, 1996: 279), en el que se constata la composición de bases de apoyo fluctuantes y fragmentadas, la acción de los nuevos liderazgos se revela central en el proceso de (re)constitución permanente de lazos de representación política. Considerando esto, justificamos una mirada que piensa a los liderazgos a partir de su capacidad creadora sobre las identificaciones de los representados (movimiento descendente del acto representativo), sin por ello dejar de considerar cómo los liderazgos inscriben su decisión en contextos histórico-institucionales que condicionan su accionar (movimiento ascendente del acto de representación). En concreto, si la propuesta de pensar a los liderazgos a partir de la representación política queda validada en virtud del movimiento circular que esta idea supone, la idea del liderazgo como lazo no pierde por ello su atributo específico: la capacidad instituyente sobre su contexto histórico de inscripción y sobre las identificaciones de los representados. ${ }^{8}$

Concretamente, en nuestro trabajo, el proceso de legitimación de los liderazgos seleccionados será pensando una doble dimensión. ${ }^{9}$ La primera de ellas comprenderá el estudio de la inscripción de los liderazgos en un determinado contexto histórico e institucional; la otra remitirá al proceso de movilización y producción de una determinada idea de la comunidad política. Es decir que nos detendremos, en la primera de estas dimensiones, en el análisis de las particularidades que hicieron a la localización de los liderazgos de Carlos Menem y Néstor Kirchner en un momento específico del devenir de la democracia argentina durante las últimas décadas. Se considerará aquí: a) la particular situación de crisis ${ }^{10}$ que marcó y condicionó la constitución de estos liderazgos; b) la organización de sus apoyos políticos ${ }^{11}$, examinando el rol que cumplieron diferentes actores (principalmente los partidos políticos y la opinión pública); c) el proceso de redefinición de las relaciones entre el Estado y la sociedad. En la segunda de estas dimensiones, se indagará de qué modo los liderazgos compusieron una idea de la comunidad política. Esto supondrá considerar, por un lado, de qué manera los mismos se presentaron como figuras representativas ${ }^{12}$ (mediante el examen de lo que aquí llamaremos "la imagen de sí mismo"13 y la "figura de la imputación"14); y por el otro, nos detendremos en el proceso de (re)creación del lazo representativo (abordando la fabricación del "auditorio-audiencia" 15 y la configuración de la idea de la "alteridad" a partir de la construcción de la figura del Otro y del establecimiento de las fronteras de identificación inclusivas y exclusivas $^{16}$ ). 


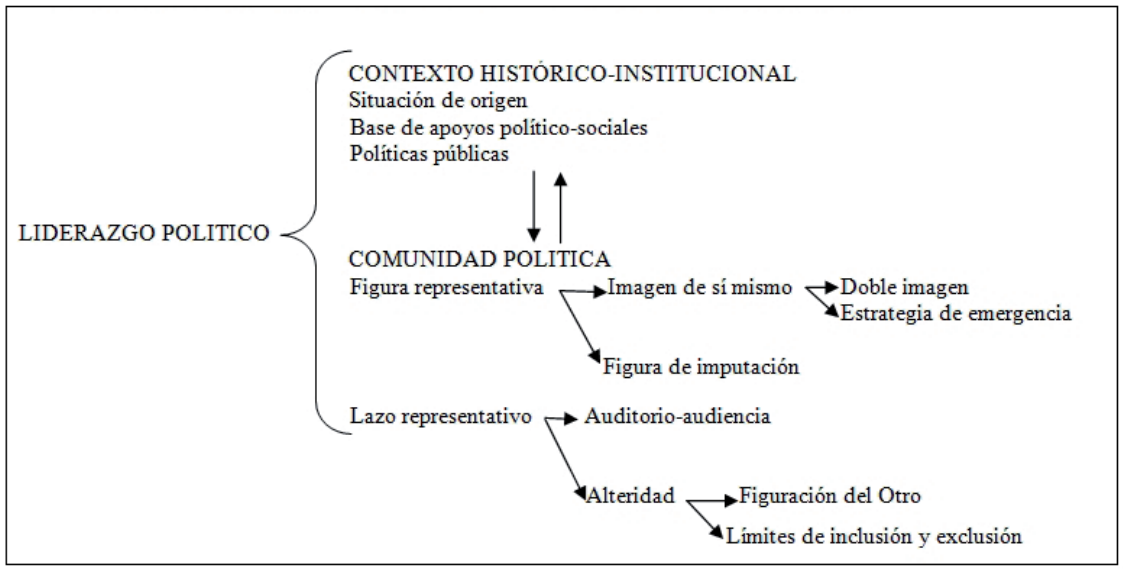

En pocas palabras, nuestra hipótesis de trabajo es que durante la fase de la constitución de los liderazgos, más allá de la diferencia que existe entre ambos, si pensamos los modelos de sociedad establecidos, sobresalen un conjunto de similitudes respecto de sus respectivas bases de apoyo político y un conjunto no menos evidente de discontinuidades, si ahora pensamos, en cada caso, los momentos que marcaron el devenir de la representación partidaria y cómo ambos liderazgos buscaron legitimar sus posiciones de poder (re)construyendo los lazos representativos y componiendo una idea de la comunidad política.

\section{El proceso de constitución de los liderazgos de Carlos Menem y Néstor Kirchner}

Comenzaremos, por el estudio del proceso de conquista del poder que protagonizó Carlos Menem luego de su triunfo en las elecciones presidenciales de 1989. Para ello, examinaremos, en primer lugar, el contexto histórico-institucional definido por el curso acelerado de la situación de crisis hiperinflacionaria, por el origen del proceso de desapego partidario y por la vertiginosa reconfiguración de las relaciones entre el Estado y la sociedad en clave neoliberal. En este marco, deliñaremos de qué modo Menem desarrolló su acción de gobierno, configurando su figura representativa y estableciendo un nuevo lazo representativo ${ }^{17}$ y tomando en cuenta, en este proceso, la relación establecida con la opinión pública y con el Partido Justicialista (PJ). En el proceso de constitución del liderazgo kirchnerista, el esquema de análisis será similar. Nuestro punto de partida será el contexto histórico-institucional definido por la superposición de un proceso de metamorfosis y crisis de la representación política (Pousadela, 2005: 257) ${ }^{18}$; por el despliegue de un inédito proceso de desarticulación del sistema partidario y, finalmente, por un proceso de transformación de la sociedad y del rol del Estado a partir de principios alternativos a los de la década de los noventa. Bajo este telón de fondo, estudiaremos la configuración de Kirchner como figura representativa y el proceso de 
recomposición del lazo representativo que dieron lugar a una nueva idea de la comunidad política.

\subsection{La situación de crisis: hacia la construcción de Menem como figura representativa}

La victoria de Menem en mayo de 1989, lejos de producir un efecto componedor respecto de la situación de crisis que vivía el país contribuyó, por el contrario, a acelerar los comportamientos especulativos de los principales sectores económicos con su correspondiente efecto en el alza sostenida de los precios internos. Asimismo, los recambios ministeriales propuestos por el gobierno y el anuncio del presidente Alfonsín del establecimiento de un plan de emergencia recibieron la indiferencia o el abierto rechazo por parte de la mayoría de los grupos de poder y las principales fuerzas nacionales del país. Hacia fines del mes de mayo, se produjeron los primeros saqueos a comercios en la ciudad de Rosario y en los barrios populares del Gran Buenos Aires (Clarín, 30/5/89). El gobierno declaró el estado de sitio y a partir de ese momento la idea de la asunción anticipada del presidente electo, pautada originalmente para el mes de diciembre, terminó de tomar cuerpo en el discurso mediático y a ganar consenso en el oficialismo y en la oposición. A mediados de junio de 1989, en un marco de descontrol generalizado, donde continuaron sin pausa los actos de violencia y los precios de los bienes entraron en una inédita espiral inflacionaria ${ }^{19}$, Alfonsín decidió -finalmente- presentar la renuncia. "Asumiré en la peor crisis de la historia" declaró en esa oportunidad Carlos Menem, futuro presidente de los argentinos (Clarín, 13/6/89). El 23 de ese mes el colegio electoral nacional consagró formalmente la fórmula ganadora en los comicios de mayo, logrando canalizar la crisis mediante los procedimientos institucionales prescriptos. Sin embargo, esto no impidió que Menem recibiera un país -literalmente- en ruinas ${ }^{20}$ : al llegar al poder sus desafíos eran no menos que gigantescos.

Así, desde los primeros días de su gestión, el mensaje que Menem buscó transmitir a la ciudadanía comprendió, en lo sustancial, la necesidad imperiosa de realizar un drástico plan de ajuste que permitiera al Estado, gracias a la instrumentación de un recorte radical de sus gastos y a una supresión considerable de sus funciones, recuperar su licuada capacidad financiera. Las ideas de reformar el aparato estatal, de desregular la economía, de privatizar los servicios públicos fueron monopolizando el programa de gobierno, en contraste abierto, con lo prometido por Menem durante la campaña electoral y en contra, principalmente, de las grandes líneas programáticas que definieron históricamente al peronismo. La situación de crisis que sufría la Argentina exigía la aplicación de soluciones drásticas y extraordinarias. El caos económico reinante redujo el conjunto de alternativas políticas provocando una situación de disponibilidad que habilitó, no sólo el curso de múltiples reconfiguraciones identitarias (Aboy Carlés, 2001: 166), sino también, la tolerancia frente a radicales procesos de transformación y ajuste estructural. En concreto, la crisis hiperinflacionaria heredada supuso, según el relato menemista, la puesta en riesgo de la comu- 
nidad política como tal. ${ }^{21}$ Fue, en definitiva, el propio lazo político, sobre el cual la misma se estructuraba que apareció dramáticamente debilitado (Sigal y Kessler, 1997: 7). ${ }^{22}$

En este marco, desde el primer momento, Menem buscó legitimarse en su rol como presidente de la Nación a través de la composición de una figura representativa que se instituyó, para empezar, a partir de una "imagen de sí mismo" según la cual él aparecía como aquel líder soberano capaz de restablecer el orden y asegurar la pacificación del país. Se buscó, de este modo, asentar la fuente de legitimidad de su liderazgo en la construcción de la imagen de un líder fuerte con capacidad de decisión para regenerar la sociedad. ${ }^{23}$ Pero, al mismo tiempo, dicha figura se duplicó en la promoción de otra imagen, ya presente durante el proceso político que marcó su llegada a la presidencia: la imagen del hombre común de lenguaje llano $\mathrm{y}$ coloquial que guiado por sus pasiones, por sus sinceros sentimientos, lograba encarnar, de forma inmediata, los deseos del pueblo. ${ }^{24}$

Asimismo, esta doble imagen se asoció con otro de los elementos que también compuso su "imagen de sí mismo": su estrategia de emergencia en tanto dirigente ajeno al mundo de la corporación partidaria. Es decir, como aquella autoridad capaz de colocarse por encima de las banderías políticas logrando expresar la unidad del cuerpo político ${ }^{25}$ y pudiendo sintonizar, de este modo, con el clima de desapego partidario que comenzaba a instalarse en la población argentina (Catterberg, 1991: 56). De este modo, la explosión de la crisis hiperinflacionaria y el origen de esta situación de desconfianza hacia los partidos fueron dos de los elementos que configuraron el contexto histórico-institucional que marcó la constitución del liderazgo menemista. Pero no fueron los únicos. Otro aspecto distintivo de dicho contexto fue su voluntad de alterarlo drásticamente a través del establecimiento de diferentes políticas públicas que fueron modificando la relación entre el conjunto de la sociedad y el propio Estado. Este proceso nos remite directamente a la otra dimensión que formó la figura representativa de Carlos Menem: la defensa del proyecto de la reforma económica constitutiva, en nuestro esquema, de su "figura de imputación". ${ }^{26}$

La necesaria realización de un proceso de transformación estructural se expresó en la puesta en marcha de dos proyectos esenciales: la reforma del Estado y la ley de emergencia económica. ${ }^{27}$ Estas dos políticas públicas dotaron de sentido a los primeros trazos de la "figura de la imputación" desde la cual Menem buscó seducir al electorado, sentando las bases de su autoridad política y legitimando la aplicación de una estrategia reformista en vistas de la constitución de lo que se conoció como "el modelo de la economía popular de mercado". Los proyectos de ley aludidos representaron, asimismo, los ejes cardinales de la gestión económica presidida por Néstor Rapanelli (representante del poderoso grupo multinacional Bunge \& Born), en el intento del gobierno de mostrar al mundo empresario su decidida vocación de realizar una reforma refundacional. Luego de un primer momento en el que la relación con los principales actores económicos estuvo marcada por la incertidumbre y la desconfianza, el curso sostenido de los proyectos de reforma fue acercando estos grupos al gobierno, dando los primeros signos de una 
alianza que se reveló tan duradera, como inédita, entre el peronismo y los sectores dominantes (Sidicaro, 2002:161)..$^{28}$

Pero para llegar a este punto, todavía faltaba recorrer un largo y riesgoso camino. Por el momento, en diciembre de 1989, y como respuesta a la nueva crisis de confianza que vivió el gobierno, el presidente Menem decidió desarticular el "modelo expresivo" con los grupos dominantes para dar paso a un otro esquema (Novaro y Palermo, 1996: 163). En efecto, con el nombramiento de Erman González como nuevo ministro de Economía, el gobierno recuperó cierta autonomía frente a estos sectores incorporando una figura perteneciente, directamente, a su propio riñón político.

\subsection{La articulación de la base de apoyos: el origen del lazo representativo menemista}

Algunos meses después, a principios de abril de 1990, en un contexto de alta incertidumbre para el gobierno se convocó a la realización de una movilización popular con el objeto de ratificar el rumbo adoptado por la gestión. El 6 de abril, la histórica plaza de Mayo se vio desbordada por una multitud superior a los 60.000 ciudadanos (Clarín, 7/4/89). Miles de personas manifestaron su apoyo al presidente Menem recreando un lazo directo con su persona y afirmando su independencia frente a cualquier tipo de maquinaria política. ${ }^{29}$ También, por supuesto, hubo una muy buena cantidad de simpatizantes de origen popular identificados con el peronismo y movilizados a través de su estructura, que por primera vez compartían la plaza con los miembros de los sectores más acomodados de la ciudad. Extrañamente, en este acontecimiento público, los polos de la escala social se encontraron en la misma vereda política, unidos en la identificación con la figura de Carlos Menem..$^{30}$ Las repercusiones de este suceso público fueron inmediatas y el vínculo entre el Presidente y el PJ entró así en su impasse más pronunciado.

La relación entre Menem y el justicialismo, desde el origen de la experiencia renovadora hasta el triunfo en los comicios presidenciales, estuvo marcada por la oscilación entre la distancia del presidente respecto de dicha estructura y su acercamiento, cuando primaron los cálculos estratégicos a la hora de sumar apoyos electorales. En esta primera etapa, Menem buscó estructurar una base de respaldos amplia, fluida, marcada por su heterogeneidad y su carácter inorgánico. En este proceso, el PJ fue no sólo desplazado de su papel de partido de gobierno (al negarle un rol activo dentro del ámbito de toma de decisiones políticas) sino que también fue relegado en tanto estructura de mediación y agregación de intereses políticos y sociales. Carlos Menem, sin dejar de referenciar su persona e inscribir su proyecto político en el universo de tradición peronista privilegió, en esta etapa, su relación con la emergente opinión pública, yendo más allá de sus clásicos respaldos.

En definitiva, la realización de la "Plaza del Sí" puso en escena la composición de un sostén más o menos articulado en torno a la necesidad de reformar el Estado, de desregular la economía y de avanzar en el proceso de privatizaciones de los activos públicos. La identificación con la figura presidencial se hizo visible a través de una masiva y sorpresiva movilización pública de respaldo: comenzaron 
a dibujarse entonces los primeros trazos de un nuevo lazo representativo. Presentemos ahora los elementos que compusieron dicho lazo.

En el contexto de una situación de crisis generalizada, Menem decidió poner en acto un mensaje a la ciudadanía, estructurado sobre la base de la necesaria apelación a la unión de todos los argentinos. ${ }^{31}$ Se intentaron borrar las separaciones y se buscó recomponer el vínculo representativo a partir de la inscripción de todos los habitantes del territorio nacional en una misma unidad de pertenencia. ${ }^{32}$ Éste fue el primero de los significados que asumió la idea de la unidad nacional; pero no fue el único (Barros, 2002: 162). Se apeló, además, a la reconciliación de los argentinos desde la construcción de un proyecto político, que instalado en el presente y de cara al futuro, proponía una síntesis entre liberalismo y peronismo pretendiendo armonizar aquellas corrientes de ideas que marcaron a fuego los trazos más importantes de la tradición política nacional, desde veredas siempre separadas y en eterno conflicto. ${ }^{33}$

Por su parte, en el proceso de construcción del público receptor del mensaje menemista, denominaciones vagas y ambiguas como "hermanos y hermanas de mi patria" serán los términos seleccionados por Menem para buscar soldar, a partir de un mensaje de notorias resonancias religiosas, la unión de todos los argentinos en una misma comunidad de pertenencia. ${ }^{34}$ Quedó definido así el límite inclusivo, desapareciendo aquel enemigo social que dio cuerpo al discurso y a la retórica del peronismo clásico (Canelo, 2005: 9). En efecto, en un contexto histórico-institucional signado por la construcción de colectivos de identificación de nacimiento repentino y muerte prematura, Menem legitimó su autoridad política trazando límites inclusivos; y cuando se definieron los exclusivos, éstos asumieron una forma novedosa. En efecto, fue distintivo de la acción menemista el establecimiento de los contornos de su público de referencia a través de una frontera que Menem intentó fijar en la negación del pasado que había precedido su asunción como presidente (Aboy Carlés, 2001: 307). ${ }^{35}$ Es decir, el pasado de la inflación, de la crisis, del proteccionismo, de la presencia asfixiante del Estado todo poderoso.

Para resumir, dicho lazo encontró en la idea de la unidad nacional su pilar de referencia. Esta idea se articuló con la creación de un nosotros inclusivo y la presencia de un límite excluyente a través del cual el enemigo social desapareció y su lugar fue ocupado por la ruptura con un pasado presentado como ominoso. La constitución del lazo supuso también la construcción de un público de referencia que en sintonía con el mensaje de unión nacional apareció despolitizado, depurado de la apelación a colectivos específicos de pertenencia y teñido de una notoria resonancia religiosa. Este proceso encontró en la multitudinaria "Marcha del Sí" su primera puesta en escena, su acto de nacimiento, para adoptar, luego del triunfo en los comicios legislativos de septiembre de 1991, y gracias a la articulación de la "figura de imputación" en torno de la idea de la estabilidad cambiaria, una forma consolidada.

A partir, entonces, de dicha convocatoria pública se fue estructurando progresivamente un apoyo sostenido, principalmente en la opinión pública, respaldando el curso de la profundización del modelo reformista, encarnado en la figura presiden- 
cial, como única salida frente a la crisis. No obstante, este esquema tendió progresivamente a modificarse (Novaro, 2009: 410). Inesperados acontecimientos que se sucedieron durante la segunda mitad del año 1990 abrieron nuevas posibilidades que habilitaron la reconfiguración de la relación entre el gobierno menemista y el PJ, y el avance en el proceso de reconstrucción de la autoridad política presidencial. ${ }^{36}$ Así también, un giro radical en dicho proceso se produjo con la aprobación del llamado "plan de convertibilidad cambiaria" impulsado por el nuevo ministro de Economía, Domingo Cavallo.

A partir del primero de abril de 1991, la ley de convertibilidad entró en vigor luego de ser aprobada por la mayoría de los diputados justicialistas y sus aliados ubicados a la derecha del espectro político (La Nación, 2/4/1990). La reorganización económica que esta ley supuso fue integral y sus primeros resultados positivos le permitieron al menemismo ir despejando progresivamente las dudas de cara a las elecciones de medio término ${ }^{37}$ en un contexto donde Menem buscó reposicionar al PJ, ahora bajo su exclusivo control ${ }^{38}$, dentro su heterogéneo universo político de referencia. En este sentido, la realización del "Congreso de Actualización Doctrinaria", a mediados del mes de marzo de 1991, fue una ilustración clara de los primeros signos de cambio en la relación entre su persona y el partido. ${ }^{39}$

Cuando llegó la hora de las urnas, la expresión de la voluntad ciudadana de apoyo a la gestión presidencial fue categórica ${ }^{40}$, revelando el carácter instituyente del liderazgo menemista. La adhesión al conjunto de reformas neoliberales y a la idea de la estabilidad que comenzaba -ahora de manera decidida- a manifestar la población, no fue el resultado de un compromiso previo ya presente en la ciudadanía (Palermo, 1999: 209). ${ }^{41}$ En lugar entonces de cumplir con una mera función expresiva, Menem constituyó su liderazgo mediante un tipo de acción que instituyó, que formó, que creó el conjunto de expectativas de la población. ${ }^{42}$ Por supuesto, dicha acción no operó en el vacío, se desarrolló en un contexto histórico e institucional que la habilitó pero, a su vez, la misma excedió cualquier marco, instituyendo algo nuevo, algo que antes no existía.

\subsection{Néstor Kirchner: el proceso de construcción de su autoridad y la emer- gencia de su figura representativa}

Casi catorce años después del triunfo menemista en 1989, aquello que definió la llegada al poder de Kirchner fue (a diferencia de la situación que marcó la victoria del ex gobernador riojano) su situación de crónica debilidad político-electoral. ${ }^{43}$ Como resultado de una fortuita sintonía de circunstancias, para fines del mes de abril, el control de los destinos de la Nación cayó -literalmente- en las manos del ex gobernador patagónico. Por delante quedaba, así entonces, un arduo camino a recorrer en el que Néstor Kirchner debía legitimar su figura frente a la ciudadanía.

Desde el primer momento, el principal desafío de su gestión fue la configuración de una base propia de apoyos y la construcción de su autoridad presidencial, en un clima de generalizada incertidumbre motivado por la difusión de desalentadores pronósticos sobre el futuro del país en el corto plazo. ${ }^{44}$ No obstante, para sorpresa 
de todos, a pocos meses de iniciado su gobierno, su liderazgo logró contar con un sostén muy importante en la opinión pública. ${ }^{45}$ Adentrémonos entonces en el estudio del proceso mediante el cual Kirchner modificó el mapa político argentino logrando la constitución de un "electorado poselectoral" (Cheresky, 2004:10). En dicho análisis, ocuparán una importancia central tanto su decisión de corte reformista, que amplió el "horizonte de lo posible", como su acción en el curso del proceso electoral de 2003, en el cual Kirchner fue perfilando su estrategia política de construcción de poder y definiendo su relación con el PJ. Ambos procesos deben pensarse en forma articulada, siendo el capital político ganado en el primer terreno lo que dotará al Presidente de capacidad de acción en el segundo. Sobre esta base, proponemos, en un primer momento, estudiar el proceso de composición de la autoridad presidencial a partir de la construcción de Kirchner como una figura representativa.

Cuando Kirchner asumió como presidente, las perspectivas de crecimiento en el terreno económico y las expectativas de salida del momento más sombrío de la crisis ya habían cobrado una realidad palpable. ${ }^{46}$ Pero aún su horizonte de superación parecía muy lejano. El contexto histórico-institucional en el que se inscribió la acción kirchnerista no sólo se definió por el despliegue de una situación de crisis, tanto en el frente económico como social, sino también por un cuadro en el que la ciudadanía, todavía bajo la inercia de la ola contestataria de 2001, se mantuvo en un estado de movilización latente. A esto cabe agregar, claro está, la extrema fragmentación del sistema partidario y la inédita ola de rechazo público hacia las mediaciones representativas. ${ }^{47}$

En este marco, la acción protagonizada por Kirchner buscó sintonizar con el conjunto de demandas que circularon durante el proceso de movilización ciudadana, desde fines de 2001 hasta bien entrado el 2002, definido -antes que nada- por su espíritu de rechazo. Al cabo de más de un año del momento más explosivo de la protesta, Kirchner recuperó dicho contexto, apropiándose de su reclamo de cambio pero buscando, al mismo tiempo, imprimirle nuevos sentidos. En otras palabras, su figura buscó identificarse con el ciclo de la inédita protesta ciudadana pero se transformó asimismo, a través del ejercicio de su autoridad, en el intérprete privilegiado de ese conjunto confuso y desarticulado de demandas. A partir del establecimiento de un proceso de reforma, la acción de Kirchner asumió así un carácter instituyente, trastocando el sentido de lo supuesto, en un contexto definido en términos de crisis. Este proceso quedó ilustrado, por un lado, en la puesta en marcha del proceso de reconfiguración de las relaciones entre el Estado y la sociedad (en sentido inverso a lo realizado durante la gestión menemista ${ }^{48}$ y en sintonía con lo que la administración duhaldista ya había insinuado ${ }^{49}$ ); pero también, en la aplicación de un conjunto de acciones que buscaron, centralmente, definir la marca distintiva de su gobierno. En líneas generales, sus medidas fundacionales tuvieron como objetivo la reestructuración de las bases de poder de distintos actores corporativos.

Sin perder tiempo, durante la primera semana de gestión, Kirchner ordenó el reemplazo de la cúpula de las fuerzas armadas (Página 12, 28/05/03). Mediante esta 
acción Kirchner inauguró el proceso de reconstrucción de la debilitada autoridad política dando forma a su imagen como líder soberano. Despejando rápidamente las dudas sobre su efectiva capacidad de decisión, el ex gobernador patagónico logró mostrarse frente a la ciudadanía en el ejercicio pleno de su voluntad transformadora derribando las murallas que protegieron -desde siempre- a históricos actores corporativos. La presentación de un liderazgo con capacidad de decisión fue entonces uno de los primeros aspectos de la composición de la "imagen de sí mismo", pero su contracara, expresada en su presentación ahora como aquel hombre que se fundía con el pueblo, encarnando inmediatamente sus deseos, no fue por ello menos importante. ${ }^{50}$ Con el ánimo de expresar el clima de la crisis de 2001, Kirchner se presentó al mismo tiempo como un líder fusional que estaba cerca de la gente y en contra de las corporaciones que distorsionaban, con su práctica representativa, la inmediata presencia de la voz del pueblo. En esta clave, durante los primeros meses de gobierno, se puso en marcha también un proceso de fortalecimiento institucional de la democracia argentina a través de la renovación de la Corte Suprema de Justicia. ${ }^{51}$ Kirchner pudo así ostentar públicamente su victoria en "la lucha contra las corporaciones" componiendo su doble imagen como líder soberano y fusional.

El otro campo en el que su capacidad de iniciativa se puso en juego fue la política de derechos humanos que, para sorpresa de todos, fue incluida como un eje cardinal de la agenda de gobierno. ${ }^{52}$ A través de esta operación comenzó a tomar forma otro de los elementos que le permitió a Néstor Kirchner configurar la "imagen de sí mismo": su estrategia de emergencia. En efecto, de manera cada vez más recurrente, la figura presidencial fue articulando su política de recuperación de la justicia con la inscripción de su persona como miembro pleno de la generación de jóvenes militantes de los años setenta. ${ }^{53}$ Era así rescatada de los sótanos de la historia la pertenencia a esa "gloriosa generación" luego de que el pensamiento político de la transición democrática la relegara radicalmente, privilegiando la afirmación de las rutinas institucionales, y de que el vendaval neoliberal la sepultara, sin miramientos, flameando victorioso la bandera del imperio de la técnica y la imposición de un mundo desapasionado, sin ideologías. ${ }^{54}$ En el mensaje oficial, en ruptura con esta configuración, el Presidente se presentó como un compañero de esa "diezmada generación", articulando desde ese lugar de inscripción la recuperación de la política, actualizada en la realización de medidas concretas de reforma y resignificada a partir de la recuperación de los principios, las ideologías y las convicciones. Pero no fue sólo la pertenencia a esta generación la posición de inscripción desde la cual Kirchner configuró su estrategia de emergencia. En la "lucha contras las corporaciones", fue tomando forma, por último, su presentación como un líder político ajeno al mundo de los partidos. Kirchner buscó la construcción de un lazo expresivo con la gente denunciando los condicionamientos propios de la oscura y subterránea realidad de los intereses partidarios. Nada parecía interponerse, en la construcción de este nuevo lazo, entre su persona y la ciudadanía, en la que Kirchner aparecía como un outsider, explotando su histórico posicio- 
namiento en la lejana periferia del PJ y sintonizando con el clima anti-partido que marcó a la crisis de 2001. ${ }^{55}$

En concreto, a partir de este conjunto de operaciones quedaron definidas las dimensiones que articularon su figura representativa. En resumen, éstas fueron: a) la presentación de la "imagen de sí mismo" a partir, por una parte, de su configuración como un líder soberano, en pleno ejercicio de la decisión política, y en tanto aquel dirigente político que no perdía el contacto inmediato con la gente. Por la otra parte, mediante la definición de su estrategia de emergencia como miembro de la generación del setenta (de la mano de la recuperación de los valores y las convicciones) y como aquel líder que se presentaba por fuera de la corporación partidaria; b) la construcción de la "figura de imputación" a partir de la realización de diferentes políticas de reforma, en el campo de los derechos humanos y de la justicia y a través de la recuperación de los indicadores macro-económicos gracias al establecimiento de un nuevo modelo de desarrollo. ${ }^{56}$

Pero si hasta ahora hemos indagado las medidas de gobierno que marcaron los inicios de la gestión, permitiéndole a Kirchner recomponer su debilitada autoridad política y registrar los primeros apoyos en la opinión pública, apenas hemos presentado el estudio de un capítulo central en el curso de su epopeya por transformar la sociedad argentina: la relación con el Partido Justicialista. ${ }^{57}$ A través de la misma, su figura representativa se actualizó y también se puso en juego. La relación con el partido será analizada a través de los procesos electorales legislativos de los años 2003 y 2005, a partir de los cuales se definieron los trazos de la base siempre heterogénea y fluida de los respaldos políticos y sociales en los que se fundó la autoridad kirchnerista.

Si como ya hemos mencionado, la acción puesta en marcha por el presidente Kirchner le permitió a la política recuperar su rol como invención y como creación, este proceso no operó en el vacío. Más allá del contexto de inscripción definido por una ciudadanía en estado de movilización, el gobierno kirchnerista encontró dos condicionamientos a su acción relacionados, ahora, con su base de apoyos. El primero, se refirió a su apelación a la fluctuante opinión pública. El segundo se relacionó con el propio origen de su gestión y el respaldo de la estructura partidaria del justicialismo, la cual al tiempo que le proveyó el necesario sustento institucional, resistió su capacidad regeneradora. ${ }^{58}$ Estas tensiones con el Partido Justicialista quedaron de manifiesto, para empezar, en las elecciones legislativas de 2003.

La decisión de los diferentes gobernadores provinciales de convocar a la realización de los comicios en sus distritos de forma escalonada, separándolos de la elección presidencial, configuró una escena político-electoral definida en tanto "proceso" ${ }^{59}$ El país se encontró así en una suerte de campaña permanente en la que los diferentes resultados que fueron dejando las urnas ritmaron la composición de la nueva escena político-partidaria. Kirchner se involucró de forma decidida en ella en el intento de lograr articular los cimientos de un poder político exclusivamente fiel a su mando. La campaña se organizó entonces en torno de su figura, asumiendo el tono de un "plebiscito prolongado" (Cheresky, 2004: 55). En este 
marco, la acción presidencial fue decisiva en el proceso de composición de la oferta política a través de una doble estrategia (Vommaro, 2004: 121). Por una parte, Kirchner buscó construir un sostén propio en el interior del peronismo, y por otra parte, avanzó en otra dirección, incitando la conformación de un espacio político que superara las fronteras de esta fuerza política. ${ }^{60}$

En pocas palabras, las elecciones legislativas de 2003 dieron cuenta, en el proceso de composición de la oferta política, del influjo del liderazgo regenerador del Presidente en una tensión-articulación con las formas más tradicionales de hacer política y, en la distribución de las preferencias electorales, de la presencia larvada de la crisis de representación. ${ }^{61}$ En definitiva, al cierre de este largo proceso electoral, el kirchnerismo salió fortalecido al obtener los primeros apoyos legislativos fieles a su proyecto ${ }^{62}$. Pero aún su acción se encuadraba bajo la tutela de la autoridad de Duhalde, quien si bien ya no detentaba la presidencia, sí podía ejercer, en función de su control sobre los representantes de la provincia de Buenos Aires, un legitimado liderazgo en el interior del Partido Justicialista.

\subsection{La estructuración del lazo representativo kirchnerista: hacia la configuración de una base propia de apoyos}

Durante los primeros meses de 2004, diferentes acontecimientos alumbraron la agudización de las tensiones entre Kirchner y Duhalde, reconfigurando el respaldo político-partidario del gobierno nacional. La conmemoración de un nuevo aniversario, a fines de marzo de 2004, del golpe militar impuesto en 1976 fue el escenario político donde el gobierno escenificó sus aspiraciones de poder redefinir sus apoyos, dotando de una mayor consistencia y continuidad a la política ya desplegada en el campo de los derechos humanos.

Si pasamos, así entonces, al análisis del proceso de creación del lazo representativo, el vasto colectivo de identificación kirchnerista quedó definido, en una primera operación, a partir del establecimiento de un límite de negación. A través de la palabra del líder, y de su acción presidencial, se delimitó aquello que debía ser abandonado para que la Argentina pudiera "salir del infierno". Si en las repetidas intervenciones públicas de Kirchner, la década de los noventa (personificada en la figura de Menem y en sus políticas) representó ese pasado que los argentinos debían dejar atrás; en el acto del 24 de marzo de 2004, se presentó el establecimiento de un nuevo límite. La representación de la "alteridad" comprendió (ahora de forma claramente definida) además del pasado neoliberal, también ese tiempo oscuro y más lejano: la dictadura militar inaugurada en marzo de 1976. En ese momento, en ese quiebre fatídico en el devenir de nuestra historia, la palabra del líder decretó la inauguración del ciclo de la decadencia argentina, estableciendo una continuidad entre aquellos años y la denigrada década de los noventa. ${ }^{63}$ A través de esta operación discursiva, todo lo realizado por la administración alfonsinista en materia de derechos humanos -más allá de sus ambigüedades y contradicciones- fue rápidamente borrado, ignorado. ${ }^{64} \mathrm{El}$ gobierno nacional se erigió entonces como el único baluarte en la lucha por la justicia estableciendo una doble ruptura: una de corto plazo frente al pasado neoliberal de los noventa y otra de largo plazo frente al 
pasado dictatorial de los setenta (Aboy Carlés, 2005: 21).Al mismo tiempo, en la figura de los "genocidas" responsables de las violaciones a los derechos humanos y en "los corruptos" protagonistas del proceso de vaciamiento del país durante la noche neoliberal, el presidente Kirchner construyó la figura de ese Otro frente al cual el proyecto nacional naciente definía sus marcas distintivas. ${ }^{65}$

Ahora bien, si por una parte el mensaje público presidencial fijó este límite exclusivo, por otra parte, el mismo supuso también una demarcación inclusiva. En este caso, se estableció la apelación a la reconstrucción de la Nación de la mano del restablecimiento del rol del Estado como principio organizador de la comunidad política; pero su función, como marco principio organizador de la sociedad, no fue el mismo que otrora le otorgó el peronismo clásico. La configuración de un nosotros excluyente de totalidad unanimista dejó su lugar, en esta etapa, a la reivindicación de la naturaleza pluralista de la sociedad argentina, afirmada en este carácter gracias al proceso de estabilización de los procedimientos institucionales. ${ }^{66}$ Esta apelación a la necesaria unidad se realizó, a su vez, mediante la recuperación de colectivos de identificación revitalizados en su naturaleza institucional y afirmados en la delimitación de su pertenencia política. ${ }^{67} \mathrm{Al}$ mismo tiempo, en esta interpelación a la reconstitución de la comunidad nacional, Kirchner se afirmaba como líder soberano, en tanto garante último de ese principio de unidad, actualizando la creación de un lazo delegativo en su relación con la ciudadanía; pero, como hemos podido también observar en el caso de Menem, dicho lazo se completó con su contracara, es decir, con el establecimiento de un vínculo fusional. Sin embargo, el mismo se inscribió ahora en un nuevo escenario: el de la "democracia inmediata" (Cheresky, 2006: 97). ${ }^{68}$

Inscripto entonces en este escenario político donde la movilización directa de la ciudadanía se superpuso con la reactualización de sus prácticas delegativas, Kirchner llevó a cabo, durante los primeros años de su gestión, el proceso de recomposición de la comunidad política, constituyendo su liderazgo a partir de su configuración como figura representativa y logrando, ya en el curso de su segundo año de gobierno, complementarla a partir del establecimiento de un lazo representativo con la ciudadanía, mediante el cual comenzó a definirse su colectivo de identificación. Particularmente, el mismo supuso: a) la creación del "auditorioaudiencia" que ahora asumía una delimitación institucional y aparecía definido a través de un marco de pertenencia; b) la definición de la idea de la "alteridad", por un lado, a partir de la demarcación de los límites exclusivos (frente al pasado dictatorial, la década de los noventa y sus respectivos actores) y de los marcos inclusivos, establecidos en la apelación a la recuperación de una idea de la Nación en clave pluralista; y por el otro, a través de la posibilidad de identificar a los adversarios del nuevo modelo de desarrollo. La definición entonces de una idea de la comunidad política (como producto del ensamble de su figura representativa y de un nuevo lazo de representación) fue dando sus primeros pasos en un proceso de largo aliento, en el cual la decisión kirchnerista fue encontrando un eco en la voluntad de los representados, demarcando así un conjunto heterogéneo de apoyos políticos. Para concluir, cabe mencionar, primero, el origen del proyecto de la 
transversalidad política durante al año 2004, y después, los avatares que el mismo experimentó en el proceso de renovación legislativa del año siguiente.

La tensión entre el proyecto encarnado por el liderazgo presidencial y el respaldo partidario del PJ se agudizó con el correr del año 2004 y alcanzó su máxima expresión a mediados del 2005. En un primer término, esta tensión se reflejó en la realización del Congreso partidario en Parque Norte a fines de marzo de 2004, escenario donde, ya sin ambigüedades, se volvió público el proyecto de la transversalidad, al tiempo que se constató también su fracaso. ${ }^{69}$ La posibilidad de que la relación entre el gobierno y el Partido Justicialista se quebrara pareció, de este modo, ser mucho más que eso. Sin embargo, durante los meses siguientes, los diferentes sectores en pugna buscaron aquietar las aguas de manera que los conflictos, puertas adentro del peronismo, no interfirieran negativamente en el curso del proyecto nacional. Pero esta situación de relativa calma se alteró cuando la escena política preelectoral, en vistas de los comicios legislativos del 2005, volvió a tensar la cuerda entre el liderazgo de Kirchner y la figura de Duhalde, abriendo el segundo capítulo del devenir de esta siempre conflictiva relación.

En pocas palabras, luego de marchas y contramarchas, de discursos de choque y de repliegue, para principios de julio, se anunció, finalmente, la presentación de las listas separadas entre el Partido Justicialista y el Frente Para la Victoria (Clarín, 3/7/05). La alianza de gobierno sufrió así un duro golpe y la división se concretó, primero, en la provincia de Buenos Aires y, luego, en distintos territorios provinciales. Así, aquello que se revelaba en contra de la lógica de la racionalidad política terminó sucediendo, desconcertando a referentes políticos de ambas orillas.

A la hora de escuchar el dictamen de las urnas, en la provincia de Buenos Aires, el triunfo del FPV sobre su rival más cercano, el PJ, fue claro y contundente. ${ }^{70}$ Las murallas del territorio bonaerense que habían logrado resistir, gracias al peso del liderazgo partidario de Duhalde y su apelación a la vigencia de la estructura justicialista y de la identidad peronista los anteriores embates de Kirchner, cayeron ahora categóricamente de la mano del mensaje oficial de la renovación de la política, habilitando la entrada del liderazgo presidencial en este estratégico distrito. ${ }^{71} \mathrm{Su}$ acción logró entonces lo que ni siquiera Carlos Menem en la cima de su popularidad había podido alcanzar a pesar de sus repetidos intentos. ${ }^{72} \mathrm{Y}$ rápidamente tanto los resultados alcanzados en el territorio bonaerense, como las victorias logradas en otros distritos, produjeron una reconfiguración de los bloques parlamentarios. ${ }^{73} \mathrm{Sin}$ embargo, estos reacomodamientos no impidieron que la coalición kirchnerista mantuviese su característico grado de heterogeneidad y fragmentación interna. Y es más, este formato más flexible, más caótico en su organización, no pareció ser un problema para el liderazgo presidencial, sino todo lo contrario. ${ }^{74}$ La constitución de este nuevo espacio ${ }^{75}$ careció, entonces, de un centro de coordinación institucionalizado, siendo la exclusiva referencia al liderazgo de Kirchner lo que le permitió mantener un relativo sentido de unidad. Y más allá de los conflictos que se desencadenaron en su seno ${ }^{76}$, el kirchnerismo inauguró, gracias a esta victoria, su entrada en la segunda fase del proceso de construcción de 
su poder político. Atrás quedó entonces el débil respaldo electoral obtenido en las elecciones presidenciales de 2003 y el acompañamiento de mayorías parlamentarias prestadas. La soledad en el poder dejó el paso a un gobierno legitimado en las urnas y con respaldos institucionales propios, determinando así el trazado de un nuevo lazo representativo y el origen del proceso de consolidación de la autoridad kirchnerista.

\section{Palabras finales: cruces y paralelos entre ambos liderazgos}

Para empezar, aparece una primera -y evidente- discontinuidad: si de la mano del liderazgo menemista la sociedad argentina devino neoliberal, a partir del liderazgo kirchnerista, la misma se volvió duramente crítica de ese modelo, alentando el establecimiento de otras configuraciones. En este proceso no pueden ignorarse las condiciones contextuales bajo las cuales Menem y Kirchner encararon, precisamente, esos procesos de transformación de la sociedad argentina. Si el principal escollo de Kirchner al llegar a la presidencia de la Nación fue enfrentar su débil legitimidad electoral, su acción política contó, sin embargo, con los beneficios que le reportaba una situación económica heredada y la constatación de una recuperación sostenida de diferentes indicadores generales. Menem, en cambio, si bien pudo hacer uso de una legitimidad tanto partidaria como ciudadana debió hacer frente a la explosión de una crisis económica que no dejó de agravarse durante los primeros años de su mandato. Estos condicionamientos (político-electorales en un caso y económicos en el otro) no pueden dejarse de lado a la hora de pensar los rasgos distintivos de ambos procesos de institución política mediante los cuales ambos liderazgos se constituyeron, en el marco de sus respectivos contextos histórico-institucionales, estableciendo una determinada idea de la comunidad política.

Sobre este proceso destacamos, en primer lugar, de qué modo Carlos Menem logró revalidar sus credenciales como máxima autoridad de la República aplicando, sobre un contexto definido por la explosión de la crisis hiperinflacionaria y el inicio del desapego de la ciudadanía frente a los partidos (en un contexto de metamorfosis de la representación) el curso de un conjunto de políticas que modificaron radicalmente la relación entre el Estado y la sociedad. En este marco, la presentación de Menem como líder soberano y como líder fusional, que emergía desde afuera de la corporación política, fueron los principales dispositivos que se pusieron en marcha para establecer su configuración en tanto figura representati$v a$. Cuando Kirchner, más de una década después, accedió a la presidencia, luego de un proceso tan accidentado como azaroso, estos dispositivos ocuparon también un lugar central en su proceso de legitimación política. Fueron entonces movilizadas tanto las imágenes del líder capaz de decidir en un contexto de caos, sin que por ello se perdiera el contacto expresivo con la gente, de la mano de una estrategia de emergencia en donde su figura aparecía por fuera de los partidos, ahora en abierta crisis. Pero si Menem presentó un mensaje donde su figura se presentaba por sobre las banderías político-partidarias, en el mismo no se buscó cuestionar a las mediaciones partidarias con la radicalidad que sí lo hizo Néstor Kirchner al buscar refundar los pilares del sistema político argentino. 
Si ahora nos detenemos, brevemente, en el lazo representativo que ambos liderazgos edificaron, podemos decir que si tanto Menem como Kirchner buscaron movilizar la idea de la unión nacional, estableciendo una definición de un nosotros inclusivo, desde la palabra pública del segundo se buscó, al mismo tiempo, apelar al regreso de la política, junto con la defensa del valor de los principios e ideologías, identificando a aquellos adversarios que debían ser excluidos de los límites de la nueva comunidad política.

En definitiva, ambos liderazgos se definieron por su carácter instituyente en tanto demostraron una consumada capacidad para redefinir los contextos históricos e institucionales en los que inscribieron su acción política dotando de un nuevo sentido a lo social. No obstante, más allá de que ambos desplegaron su decisión en tiempos de crisis, es en las discontinuidades en los formatos de representación partidaria, que marcaron a cada momento de la democracia argentina, y en los quiebres de las formas movilizadas para reconstruir los lazos representativos donde es posible identificar, más allá del tipo de modelo socio-económico encarnado por Menem y Kirchner, las diferencias más claras entre ambos liderazgos presidenciales en su fase de constitución.

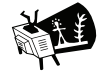

\section{Referencias}

1. En este caso, decidimos concentrarnos en el "proceso de constitución" de los liderazgos dejando de lado tanto su "proceso de emergencia" (1983-1989/1999-2003) como su "proceso de consolidación" (1991-1995/2005-2007).

2. Nuestra estrategia metodológica comparativa se inscribe, primero, en un análisis de tipo diacrónico. En segundo lugar, propone el examen denso de determinados contextos históricos siendo nuestros objetivos, centralmente, descriptivos e interpretativos. Respecto de las técnicas de recolección de datos, las mismas fueron, por un lado, las entrevistas en semi-profundidad realizadas durante el trabajo de campo entre los años 2004 y 2008, centralmente en la Provincia de Buenos Aires; y por el otro, el relevamiento gráfico y audiovisual de los diferentes medios de prensa, la recolección de los documentos partidarios, de los informes de consultoría pública y la selección de los discursos presidenciales. En relación con estos últimos se tomaron en cuenta, principalmente, los mensajes dirigidos a una audiencia nacional y a un público político-partidario. En este sentido, estableciendo que "toda acción política no es comprensible fuera del orden simbólico que la genera" (Sigal y Verón, 2003: 15), aclaremos que no es nuestra meta el estudio en sí de los discursos movilizados y producidos por ambas figuras políticas, sino que los mismos fueron incluidos como instrumento de análisis para cumplir con nuestro objetivo de estudio.

3. Sólo buscamos definir la mirada analítica desde la cual analizaremos nuestro objeto de estudio. Para un estudio de las diferentes visiones desde las cuales se pensó el fenómeno del liderazgo político, ver Rodríguez (2012: 38-74).

4. La idea del liderazgo como relación no aparece de manera explícita en la obra de Weber. De hecho en ella permanece la tensión respecto de la idea de pensar al líder en función de sus capacidades heroicas y excepcionales, como atributo esencial de la dominación de tipo carismática, y la posibilidad de ir más allá de esta idea, concibiendo su proceso de objetivización.

5. Como ejemplo de la primera cabe mencionar el clásico estudio de McGregor Burns (1978) o el más reciente trabajo de Edwards III (2009), entre los representantes de la segunda, sobresalen entre otros los trabajos de Blondel (1987) y de Elgie (1995).

6. Fabbrini (2009:10) plantea en este sentido una productiva distinción entre la idea del líder y del liderazgo. Si el primero alude al actor; el segundo, remite a una relación inscripta en un determinado contexto. 
7. Esta visión se enmarca en la perspectiva desarrollada por Claude Lefort para quien lo político se define por el proceso de puesta en forma de lo social siendo la democracia un tipo de sociedad definida por el principio de la indeterminación. Para un detalle sobre este punto, ver Lefort (1986:10-31).

8. Este rol de los liderazgos se ha visto potenciado, particularmente en el caso argentino, dados los diferentes aspectos que han distinguido a su régimen político: la tardía constitución del sistema partidario, el híper-presidencialismo, los procesos de metamorfosis de la vida política, las situaciones de crisis del lazo representativo y el lugar del peronismo. Para un análisis sobre este punto, ver Rodríguez (2012: 59-114).

9. Dos comentarios valen en este sentido. Primero, la distinción entre ambas dimensiones tiene un carácter claramente analítico, en nuestro análisis las mismas serán abordadas en forma articulada. Segundo, afirmamos que tanto en una como en la otra se revela el carácter formador del liderazgo.

10. La idea de "situación de crisis" recupera lo planteado por Aboy Carlés (2001: 165) y Barros (2002: 150).

11. Recuperamos aquí algunos de los argumentos ya presentados en Rodríguez (2014).

12. La idea de la figura representativa remite a la conceptualización que nos propone Novaro (2000: 164).

13. Desde una visión perteneciente al análisis del discurso político e inscripta en la corriente francesa, la imagen de sí mismo se corresponde con el concepto de ethos. Para un análisis en este sentido, ver Charaudeau y Maingueneau (2002: 238).

14. En los términos de Le Bart (1998: 84-85), el discurso de la imputación designa al conjunto de enunciados por los cuales el hombre político establece un lazo de causalidad entre aquello que él ha hecho (la decisión) y aquello que se constata (la realidad social).

15. El auditorio se entiende como aquella audiencia, en su configuración más vasta, al que el líder constituye a través de su palabra pública (Charaudeau y Maingueneau, 2002:172). Asimismo, adaptando dicha categoría a nuestro marco de análisis, optamos por presentar la idea del auditorio-audiencia considerando los rasgos constitutivos del modelo de la democracia de lo público (Manin,1996: 279302).

16. Entenderemos la idea de "alteridad" como la representación de aquello que el líder excluye en su mensaje público a los fines de constituir su propio colectivo de identificación (Charaudeau y Maingueneau, 2002: 32 y Aboy Carlés, 2001: 66).

17. Aunque es posible concebir que ambos procesos se desplegaron de forma consecutiva no desconocemos la porosidad de sus fronteras.

18. Si el primer proceso alude a las mutaciones generales en la vida política (Manin, 1996) el segundo remite particularmente a la situación de cuestionamiento del lazo representativo. Tomando en cuenta este cruce particular entre procesos y momentos que marcó a la democracia argentina es dable identificar, también, los atributos distintivos de los nuevos liderazgos.

19. El índice inflacionario de junio fue del $114.5 \%$ en el costo de vida (Clarín, 7/7/89). Durante el mes de julio; se registró un aumento del costo de vida del 196.6\% (Clarín, 8/8/89).

20. En comparación con 1988, el PBI experimentó en 1989 una caída del $6.2 \%$, la producción industrial un descenso del $4.8 \%$, la actividad agrícola del 9.2\%, la construcción un retroceso del $24.4 \%$ y el desempleo aumentó del 3.9\% al 7.3\% (Acuña, 1995: 70).

21. Las referencias a esta crisis, que asumiría un carácter terminal, fueron constantes en los mensajes presidenciales. A modo de ejemplo, Menem afirmaba: “...Recibimos -y este no es un pretexto, todo el mundo lo sabe- un país sumergido en lo profundo de un abismo económico-social. Con las reglas de convivencia económica civilizada rotas. Con el espectro de la disgregación social convertido en siniestra realidad..." (30/11/1989).

22. La situación hiperinflacionaria fue entonces la dimensión central que definió a dicho contexto de crisis, entendida, centralmente, a partir de la dilución de la legitimidad en la autoridad política a la hora de asegurar la existencia de un orden viable (Quiroga, 2005: 122).

23. En este sentido, Menem sostenía: “...Como mandatario de la ciudadanía, tenía una necesidad dramática el último 8 de julio. $O$ me transformaba en un simple testigo de la crisis, o me decidía a encarar una transformación en serio..." (1/5/1990). 
24. Este tipo de operación quedó también ilustrada, primero, en su participación en eventos deportivos (que daban cuenta de un presidente "humanizado") y en programas televisivos (desde los cuales renovaba su contacto cotidiano con la gente), pero también a partir de su decisión de difundir públicamente sus problemas privados, quebrando así la frontera que protegía la esfera más reservada de su intimidad.

25. Aparece aquí la apelación a la unidad de todos los argentinos como dispositivo clásico de la enunciación discursiva peronista (Canelo, 2005).

26. Aclaremos que la "figura de imputación" comenzó apenas a articularse hacia el fin de 1989, para asumir una forma más acabada ya entrado su tercer año cuando se puso en marcha el plan de convertibilidad cambiaria, dando origen al proceso de consolidación de su autoridad política.

27. El primero buscó la desarticulación de los mecanismos que dieron lugar a la consolidación del modelo del capitalismo asistido en la Argentina desde mediados de los años cuarenta (Torre y Gerchunoff, 1996: 736). El segundo tuvo como fin desmontar otro de los pilares del patrón de desarrollo preexistente, al fijar el marco normativo para la privatización de diferentes servicios públicos (ferrocarriles, rutas y puertos) y de distintas empresas estatales.

28. Otro indicador claro, en este sentido, fue la decisión de Menem de incorporar a la alianza de gobierno a buena parte del elenco partidario de la UCEDE, fuerza ubicada a la derecha del espectro político y defensora a ultranza de las máximas del liberalismo económico.

29. Ver, en este sentido, la encuesta de opinión según la cual el 63\% de los participantes expresó que votaría en ese momento por Menem y que sólo el 10\% lo haría por el PJ (Clarín, 15/4/1989).

30. Se anticiparon así los rasgos centrales de la coalición política en la que se respaldará electoralmente el Presidente durante los años sucesivos para alcanzar, en los comicios presidenciales de 1995, su expresión más acabada (Gervasoni, 1998: 9).

31. Durante el acto de repatriación de los restos de Juan Manuel de Rosas, el Presidente afirmaba: “... Yo no soy el presidente de un país partido por mitades. Yo no soy el jefe de una familia desunida. Yo no soy el administrador de un hogar en desgracia. Yo no soy el impostor de una fugaz esperanza, ni el demagogo de un próximo desencanto. Soy el presidente de todos los argentinos..." (30/9/1989).

32. Esta operación se corresponde también con la construcción de la "imagen de sí mismo" a partir tanto de su imagen como líder soberano que encarnaba al conjunto de la comunidad como de su "estrategia de emergencia", en la que él aparecía por encima de las divisiones partidarias. Pero si, por un lado, Menem construyó un tipo de lazo delegativo en el que su figura reunía el poder máximo de mandar en el terreno de una democracia donde la ciudadanía asumió una posición pasiva y desencantada (O’Donnell, 1992: 12); por el otro, Menem, como ya hemos examinado, buscó instalar su imagen de hombre común. A partir entonces de esta doble imagen se organizó ahora el lazo delegativo y fusional entre su liderazgo y la ciudadanía.

33. En el terreno partidario, esta interpelación discursiva se concretizó en el conjunto de alianzas, a las que ya hemos hecho referencia, entre el menemismo y tanto la derecha liberal como los grupos del poder económico.

34. Aparece actualizada, en esta operación, la dimensión carismática que definió al liderazgo de Menem. Para un análisis en esta clave, ver Arias (1995).

35. Aclaremos que esta frontera logrará consolidarse una vez establecido el plan de estabilidad cambiaria.

36. Nos referimos al proceso que abrió la derrota de Cafiero en las elecciones bonaerenses de agosto de 1990 y al hecho de que Menem lograra, poco tiempo después, hacerse con el control de la estructura nacional del PJ.

37. Desde el mes de mayo de 1991, los aumentos en los precios fueron decreciendo. En julio se registró una suba del 2.6\% en el costo de vida, siendo la más baja desde febrero de 1986 (Clarín, 3/08/91). A partir del mes de septiembre ya se constató un proceso de deflación en los precios internos (Clarín, 4/9/91).

38. La oferta política en el plano nacional dio cuenta de la subordinación de dicha estructura partidaria a la autoridad menemista a través de la incorporación de candidatos "outsiders" impulsados directamente por la figura presidencial. 
39. Muy brevemente, realizado en un contexto de palmaria incertidumbre, a pocas semanas de consumado el nuevo recambio ministerial en la cartera económica, Menem encontró una mayor receptividad en los sectores más representativos del justicialismo de cara al necesario sostén del rumbo político y económico (Clarín, 17/3/91).

40. El PJ triunfó en diez de las doce provincias que renovaron sus autoridades legislativas y ejecutivas en septiembre. Sumando los porcentajes que obtuvo el gobierno nacional durante el proceso electoral, entre los meses de agosto y diciembre, el mismo alcanzó el $40.22 \%$ de los votos. Conquistó un total de 61 diputados y relegó a un lejano segundo lugar al radicalismo, con un $29.03 \%$ de los votos (Ministerio del Interior, República Argentina).

41. Según el sondeo de opinión publicado en Mora y Araujo (2011:31) dichas preferencias en 1985 eran del $13 \%$, mientras que las desarrollistas, las corporativistas y las que estaban a favor de un estatismo clásico sumaban un 49\%. En 1989 la suma de estas últimas, en medio de la crisis hiperinflacionaria, habían bajado al 33\% mientras que las neoliberales aumentaron a un $22 \%$ y para 1992 se redujeron a un $19 \%$ y las favorables a un orden neoliberal ya eran mayoritarias, con un $38 \%$.

42. La aprobación al gobierno nacional fue del $41 \%$ en mayo de 1991 y alcanzó cerca del $70 \%$ en diciembre de ese mismo año (Informe IPSOS, 2008).

43. En efecto, la victoria de Kirchner fue el resultado del módico apoyo que el Frente para la Victoria (FPV) recibió en las elecciones presidenciales de abril de 2003 (apenas un $22.24 \%$ de los votos) y de que buena parte de dicho respaldo lo obtuvo como resultado de la alianza política consumada con el ex presidente Eduardo Duhalde (2002-2003). Pero, además, a esto se le sumó la decisión de Carlos Menem, ganador de la primera vuelta, de no presentarse en el segundo turno electoral, negando entonces la posibilidad de que el candidato santacruceño validara su nominación a partir del respaldo de una nítida mayoría electoral.

44. Ver al respecto, por ejemplo, la edición del 15/4/03 del diario La Nación.

45. Según la consultora Poliarquía, en el mes de julio de 2003, un $83 \%$ de la población tenía una imagen positiva de Kirchner. La misma fue siempre superior al 55\% hasta el fin de su mandato (Clarín, 25/05/07).

46. Kirchner heredó por primera vez en décadas un país que, aunque ostentaba un panorama muy negativo en el terreno social (con alarmantes índices de pobreza y desempleo) contaba con un PBI en expansión, una inflación controlada y un relativo orden en materia fiscal (Cherny et al., 2010: 22).

47. Según el estudio de Latinobarómetro (2003) sólo el 8\% de la población argentina manifestaba confiar mucho o algo en los partidos políticos.

48. Lo que no obsta que podamos identificar también elementos de continuidad en relación, por ejemplo, con la configuración de un patrón de acción estatal débil en términos institucionales. Ver al respecto, Bonvecchi (2011: 151).

49. El gobierno kirchnerista alentó el establecimiento de un modelo centrado en el fortalecimiento de la capacidad de consumo del mercado interno y en la intervención del Estado en la economía, mediante un esquema de control de precios, de aumento del gasto público, de fijación de diferentes subsidios, de un proceso de re-industrialización de la economía y de la puesta en marcha de una política de nacionalización de distintos sectores estratégicos. Vale agregar que, cuestionando el intervencionismo estatal indiscriminado, la atención a los equilibrios macroeconómicos devino, a diferencia del pasado, una obsesión de la administración nacional.

50. Esta idea aparece claramente en numerosos pasajes de sus mensajes públicos. Citando solamente algunos de sus extractos, Kirchner sostenía: “....No me van a colocar ningún by pass en el medio para conectarme con la gente. Las viejas corporaciones políticas le han hecho mucho daño al país y es mejor el contacto directo con la población para alcanzar las soluciones más rápido..." (La Nación, 17/08/05). Asimismo, esta imagen se expresó mediante un particular estilo político en el cual sobresalió la vocación de Kirchner de sortear las formalidades del protocolo presidencial buscando, si la situación lo permitía, mezclarse con la gente en cada acto gubernamental, sumergiéndose de lleno en ese mar de contención emocional que el público movilizado prodigaba a su figura.

51. Su gestión cobró un vértigo inesperado -que se transformaría luego en su marca registrada- el nuevo mandatario estableció un radical proyecto de renovación de la Corte Suprema que concluyó con 
la desarticulación de la denostada "mayoría automática" edificada durante los años menemistas.

52. En la primera semana de junio de 2003, el Presidente recibió a los referentes de los principales agrupamientos políticos en lucha. Luego, en agosto de ese mismo año, el Congreso estableció la nulidad de las "Leyes del Perdón" (denominación pública de las leyes de Punto Final y de Obediencia Debida), permitiendo que la Cámara Federal de Justicia pudiera reabrir las causas por los crímenes de lesa humanidad cometidos durante la última dictadura militar.

53. En uno de los extractos de su mensaje de asunción, de mayor circulación mediática y de recurrente referencia por parte de la base militante kirchnerista, Néstor Kirchner afirmó: “...Formo parte de una generación diezmada, castigada con dolorosas ausencias; me sumé a las luchas políticas creyendo en valores y convicciones a las que no pienso dejar en la puerta de entrada de la Casa Rosada..." $(25 / 5 / 2003)$.

54. El mensaje kirchnerista al tiempo que proponía un rescate de los valores de aquella generación se revelaba actualizado en tanto no negaba -sino que valorizaba y reconocía explícitamente- la huella pluralista que dejó el saludable proceso de normalización institucional de los años ochenta.

55. Recordemos que durante toda su presidencia Kirchner rechazó, a diferencia de Menem, presidir el PJ y que durante la primera etapa de su gobierno se negó a recibir en el despacho presidencial a los legisladores y a los gobernadores justicialistas.

56. Cabe mencionar también, en este sentido, la central decisión del gobierno de negociar la deuda externa frente a los organismos internacionales de crédito (Página 12, 12/09/03).

57. Para un análisis en detalle sobre este punto, ver Ollier (2005).

58. Claras diferencias surgieron, ya en esta primera etapa, entre Kirchner y Duhalde, en temas como la política de derechos humanos y en la relación con los movimientos sociales de protesta.

59. El ciclo electoral se inauguró en las provincias de La Rioja y Santiago del Estero, a fines del mes de abril, y culminó siete meses después cuando se llevaron a cabo las elecciones provinciales en los distritos de Corrientes, Entre Ríos, San Luis y Tierra del Fuego.

60. Esto quedó ilustrado, centralmente, en distritos como Río Negro y la Ciudad de Buenos Aires.

61. Por un lado, quedó ilustrado el efecto configurante del liderazgo presidencial sobre la definición de las candidaturas derribando las barreras partidarias (aunque la referencia al caso de la provincia de Buenos Aires y la resistencia que impuso la autoridad de Duhalde dieron cuenta también de sus límites); por el otro, los fenómenos del voto en blanco y la abstención reflejaron la persistencia de la desafección partidaria en el comportamiento del electorado.

62. Los resultados de este proceso le permitieron al gobierno alcanzar una ajustada mayoría absoluta en la cámara baja, con 129 bancas (Cherny et al., 2010: 30).

63. Afirmaba Kirchner en este sentido: “...Dejar atrás esa vieja Argentina que hasta hace muy poco tiempo martirizó a todos los argentinos en el marco de la conducción y el proyecto político que tuvo este país lamentablemente de manera fundamental en la última década del '90, pero que se inició en marzo de 1976 hasta la explosión de 2001 ..." (21/08/03).

64. En el mensaje pronunciado el día de la apertura del Museo de la Memoria, Kirchner declaró: “... Como Presidente de la Nación Argentina vengo a pedir perdón de parte del Estado nacional por la vergüenza de haber callado durante 20 años de democracia por tantas atrocidades..." (24/04/04).

65. La figura del adversario político-social volvía así a ocupar un status público frente al silenciamiento al que la sometió el mensaje menemista, estableciendo una continuidad con uno de los elementos constitutivos del discurso peronista o con el populismo como forma particular de construcción de una identidad política (Aboy Carlés, 2005).

66. Nación y democracia dejaron entonces de presentarse como entidades irreconciliables, definiendo los trazos distintivos de la emergencia de un "populismo atemperado" (Aboy Carlés, 2005: 22).

67. Nuevamente remarcando su ruptura respecto del fatídico interregno menemista, Kirchner se dirigió a su auditorio, nombrándolo, en términos de "ciudadanos y ciudadanas", en sintonía con su discurso de defensa de un "país normal" (Donot, 2014: 4) y como "pueblo de mi patria", principalmente en la etapa 2003-2005, y en términos más generales, como "argentinos", comprendiendo ahora todo el período 2003-2007 (Montero, 2007: 324).

68. Es decir, en un contexto definido por una presencia ciudadana en el espacio público, en el que se 
actualizó un formato de movilización novedoso signado por la ausencia de mediaciones representativas, por la presencia de reclamos puntuales, por el poder de veto, por la escenificación del mundo privado, y finalmente, por un decisivo, pero efímero, poder de influencia. Las marchas en el contexto de la crisis de 2001 y las movilizaciones de la seguridad en 2004 en diferentes ciudades del territorio nacional fueron, entre otras, claros ejemplos de este nuevo formato.

69. Este proyecto tuvo como meta, en un primer momento, encaminar un proceso de transformación del justicialismo, en clave reformista, incorporando sectores del peronismo de izquierda y no peronistas para lograr controlar esta estructura (Torre, 2004:1). Luego del Congreso de Parque Norte, el mismo será re-significado en términos de la construcción de una base amplia de apoyos más allá de los límites del peronismo.

70. Cristina de Kirchner obtuvo un poco más del $40 \%$ de los votos en todo el distrito con una diferencia de más de $20 \%$ respecto a su competidora más próxima, Hilda de Duhalde. Para un análisis sobre este proceso electoral, ver Rodríguez (2006: 209-240).

71. Este proceso es analizado por Ollier $(2005: 176)$ en términos del despliegue de un efecto nacionalizador sobre la política bonaerense.

72. Creemos que el peso del liderazgo duhaldista y el curso de los procesos de metamorfosis y de crisis de la representación partidaria presentes en el escenario bonaerense, más allá de sus particularidades, deben ser las dimensiones a considerar a la hora de poder explicar esta diferencia.

73. El kirchnerismo logró sumar, pocos meses después de las elecciones, un total de 107 legisladores propios, mientras que el justicialismo disidente reagrupó alrededor de 40 legisladores (La Nación, 31/08/05). Durante el 2006, los "saltos de vereda" en el interior del peronismo no se hicieron esperar y el FPV pudo consolidar un clara mayoría legislativa en ambas cámaras.

74. Si en el caso de Menem luego de los comicios de 1991 el PJ devino el partido de gobierno (Novaro, 2009: 410) durante la fase de consolidación del liderazgo de Kirchner, si bien el justicialismo se integró a la coalición oficial, ocupó dentro de ella una posición subordinada y en conflicto con el resto de los actores políticos sociales que compusieron la fluida "galaxia kirchnerista".

75. Concretamente, la variopinta alianza de gobierno se compuso a partir de la agregación de diferentes actores: los organismos de defensa de los derechos humanos; las organizaciones sociales de protesta; los diferentes sectores del sindicalismo y las representaciones empresariales; los dirigentes extra-partidarios o ajenos al peronismo; y finalmente, el magma de dirigentes partidarios de origen provincial, inscriptos en la estructura territorial del PJ y poco dispuestos a resignar el control de sus bases locales de poder.

76. Precisamente, desde 2006, las tensiones se multiplicaron entre los referentes transversales y los representantes de la estructura justicialista, incorporados en masa luego de la derrota de 2005. Para un análisis sobre la relación entre el kirchnerismo y los movimientos sociales, ver Natalucci-Pérez (2010).

\section{Bibliografía}

G.ABOY CARLÉS (2001), Las dos fronteras de la democracia argentina, Rosario, Homo Sapiens.

G.ABOY CARLÉS (2005), "Populismo y democracia en la Argentina contemporánea", Revista de Estudios Sociales, Santa Fe, Año XV, No 27.

C.ACUÑA (Comp.) (1995), La nueva matriz política argentina, Buenos Aires, Nueva Visión.

M. ARIAS (1995), "Charismatic leadership and the transition to democracy. The rise of Menem in Argentinean politics", University of Texas, Paper $\mathrm{N}^{\circ}$ 95-02.

S. BARROS (2002), Orden, democracia y estabilidad, Córdoba, Acción Editora.

J. BLONDEL (1987), Political Leadership. Towards a General Analysis, London, SAGE P.

A. BONVECCHI (2011), "Del gobierno de la emergencia al capitalismo selectivo: las relaciones Estado-empresarios durante el kirchnerismo", en M. DE LUCA y A. MALAMUD (Comps.), La politica en tiempos de Kirchner, Buenos Aires, EUDEBA.

P. CANELO (2005), "Las identidades políticas en la Argentina de los años noventa. Rupturas y continuidades entre peronismo y menemismo", Revue de Civilisation Contemporaine, Université de Bretagne, $\mathrm{N}^{\circ} 5$. 
E. CATTERBERG (1991), Argentina confronts politics: political culture and public opinion in the Argentine transition to democracy, Boulder, Rienner.

P. CHARAUDEAU y D. MAINGUENEAU (2002), Dictionnaire d'analyse du discours, Paris, Seuil.

I. CHERESKY (2004), "Cambio de rumbo y recomposición política", Nueva Sociedad, Caracas, $\mathrm{N}^{\circ} 193$.

I. CHERESKY (2006), "La ciudadanía y la democracia inmediata" en I. CHERESKY (Comp.), Ciudadanía, sociedad civil y participación política, Buenos Aires, Miño \& Avila.

N. CHERNY, G. FEIERHERD y M. NOVARO (2010), "El presidencialismo argentino: de la crisis a la recomposición del poder”, América Latina Hoy, Universidad de Salamanca, Vol. 54.

M. DONOT (2014), "El retorno del pueblo en la retórica kirchnerista: entre la recuperación de la tradición peronista de izquierda y las nuevas formas de la política", Actas del Coloquio AHILA, Cádiz.

G. EDWARDS III (2009), Strategic President. Persuasion and Opportunity in Presidential leadership, Princeton University Press.

R. ELGIE (1995), Political Leadership in Liberal Democracies, Hampshire, McMillan.

S. FABBRINI (2009), El ascenso del Príncipe democrático. Quién gobierna y cómo se gobiernan las democracias, Buenos Aires, Fondo de Cultura Económica.

C. GERVASONI (1998), "Del distribucionismo al neoliberalismo. Cambios en la coalición electoral peronista durante el gobierno de Carlos Menem”, Documentos Universidad Torcuato Di Tella, Buenos Aires.

E. LACLAU (1998), "Deconstrucción, pragmatismo y hegemonía", en CH. MOUFFE (Comp.), Deconstrucción y pragmatismo, Buenos Aires, Paidós.

C. LE BART (1998), Le discours politique, Paris, Presses Universitaires de France.

C. LEFORT (1986), Essais sur le politique, Paris, Seuil.

J. MACGREGOR BURNS (1978), Leadership, New York, Harper \& Row.

B. MANIN (1996), Principes du gouvernement représentatif, Paris, Flammarion.

S. MONTERO (2007), "Política y convicción. Memorias discursivas de la militancia setentista en el discurso presidencial argentino", Revista ALED, Vol.7, №2.

M. MORA y ARAUJO (2011), La Argentina bipolar. Los vaivenes de la opinión pública (1983-2011), Buenos Aires, Sudamericana.

A. NATALUCCI y G. PÉREZ (2010), "La matriz movimientista de la acción colectiva en Argentina: la experiencia del espacio militante en Argentina", América Latina Hoy, Universidad de Salamanca, Vol.54.

M. NOVARO (2000), Representación y liderazgo en las democracias contemporáneas, Rosario, Homo Sapiens.

M. NOVARO (2009), Argentina en el fin de siglo. Democracia, Mercado y Nación (1983-2001), Buenos Aires, Paidós.

M. NOVARO y V. PALERMO (1996), Política y poder en el gobierno de Menem, Buenos Aires, Norma.

G. O’DONNELL (1992), “¿Democracias delegativas?”, Cuadernos del CLAEH, Montevideo, Año 17, $\mathrm{N}^{\circ} 61$.

V. PALERMO (1999), “¿Mejorar para empeorar? La dinámica política de las reformas estructurales en Argentina" en M. NOVARO (Comp.), Entre el Abismo y la Ilusión. Peronismo, democracia y mercado, Buenos Aires, Norma.

M. OLLIER. (2005), "Liderazgo presidencial y jefatura partidaria: entre la confrontación y el pacto (2003-2005)", Revista Temas y Debates, Año 9, № 10.

I. POUSADELA (2005), "Mutaciones de la representación política en la argentina contemporánea", Tesis de Doctorado, Universidad de Belgrano, Buenos Aires.

H. QUIROGA (2005), La Argentina en emergencia permanente, Buenos Aires, Edhasa.

D. RODRIGUEZ (2006), "Liderazgos y partidos partidos: la fractura del justicialismo y la reconfiguración del escenario político en la Provincia de Buenos Aires", en I. CHERESKY (Comp.), La politica después de los partidos, Buenos Aires, Prometeo. 
D. RODRIGUEZ (2012), "Liderazgos presidenciales en tiempos de crisis y transformaciones en los formatos representativos de la democracia argentina. Los casos de Néstor Kirchner (2003-2007) y Carlos Menem (1989-1995) en perspectiva comparada", Tesis de Doctorado, Instituto de Estudios Políticos de Paris, Sciences Po.

D. RODRIGUEZ (2014), "Populismo y liderazgos en la democracia argentina. Un cruce comparativo entre el menemismo y el kirchnerismo", Revista POSTData, Vol.19, ํㅜ 2.

R. SIDICARO (2002), Los tres peronismos. Estado y poder económico. 1946-55/1973-76/1989-99, Buenos Aires, Siglo XXI.

S. SIGAL y G. KESSLER (1997), «Comportements et représentations face à la dislocation des régulations sociales: l'hyperinflation en Argentine », Culture \& Conflits, $\mathrm{N}^{\circ} 24-25$.

S. SIGAL y E. VERON (2003), Perón o muerte. Los fundamentos discursivos del fenómeno peronista, Buenos Aires, Eudeba.

J. C. TORRE y P. GERCHUNOFF (1996), "La política de la liberalización económica en la administración de Menem”, Desarrollo Económico, Buenos Aires, Vol.36, Nº143.

J. C. TORRE (2004), "La operación política de la transversalidad. El presidente Kirchner y el Partido Justicialista", Universidad Torcuato Di Tella, 2004.

G. VOMMARO (2004), «Comment sortir de la crise? Organisation partisane et volonté politique sous le gouvernement Kirchner », Paris, Cahiers d'Amérique Latine, Nㅜ46.

M. WEBER (1991), Escritos Politicos, Madrid, Alianza.

\section{Fuentes citadas}

\section{Discursos presidenciales}

-Selección de mensajes públicos del Presidente Dr. Carlos Saúl Menem a partir de la base de datos disponible en: http: //lanic.utexas.edu/larrp/pm/sample2/argentin/menem/index.html

-Selección de mensajes públicos del Presidente Dr. Néstor Kirchner a partir de la base de datos disponible en: http: //www.casarosada.gov.ar/discursos-2007?start=2140

\section{$\underline{\text { Archivo gráfico }}$}

-Diarios nacionales: Clarín (1989/1991 y 2003/2005) y La Nación (1989/1991 y 2003/2005)

-Informes de opinión pública: IPSOS (1989-1991), Poliarquía (2003-2005), Latinobarómetro (2003)

Recibido: 17/02/2014. Aceptado: 20/06/2014.

Darío Rodríguez, “Los nuevos jefes democráticos. Carlos Menem y Néstor Kirchner en clave comparada". Revista Temas y Debates. ISSN 1666-0714, año 18, número 28, julio-diciembre 2014, pp. $31-54$. 